STRUCTURAL BIOLOGY COMMUNICATIONS

ISSN 2053-230X

Received 26 April 2021

Accepted 23 September 2021

Edited by M. A. Hough, University of Essex, United Kingdom

Keywords: iron-sulfur proteins; Shethna protein I; Azotobacter vinelandii.

PDB reference: [2Fe-2S] protein I from Azotobacter vinelandii, $5 \mathrm{abr}$

Supporting information: this article has supporting information at journals.iucr.org/f

\section{Crystal structure of the [2Fe-2S] protein I (Shethna protein I) from Azotobacter vinelandii}

\author{
Burak V. Kabasakal, ${ }^{a, b}$ Charles A. R. Cotton ${ }^{a, c}$ and James W. Murray ${ }^{a *}$ \\ ${ }^{\mathbf{a}}$ Department of Life Sciences, Imperial College London, Exhibition Road, London SW7 2AZ, United Kingdom, ${ }^{\mathbf{b}}$ Turkish \\ Accelerator and Radiation Laboratory, Institute of Accelerator Technologies, Ankara University, Gölbaşı, 06830 Ankara, \\ Turkey, and ${ }^{\mathrm{c} C a m b r i u m ~ G m b H}$, Max-Urich-Strasse 3, 13355 Berlin, Germany. *Correspondence e-mail: \\ j.w.murray@imperial.ac.uk
}

Azotobacter vinelandii is a model diazotroph and is the source of most nitrogenase material for structural and biochemical work. Azotobacter can grow in above-atmospheric levels of oxygen, despite the sensitivity of nitrogenase activity to oxygen. Azotobacter has many iron-sulfur proteins in its genome, which were identified as far back as the 1960 s and probably play roles in the complex redox chemistry that Azotobacter must maintain when fixing nitrogen. Here, the $2.1 \AA$ resolution crystal structure of the [2Fe-2S] protein I (Shethna protein I) from $A$. vinelandii is presented, revealing a homodimer with the [2Fe-2S] cluster coordinated by the surrounding conserved cysteine residues. It is similar to the structure of the thioredoxin-like [2Fe-2S] protein from Aquifex aeolicus, including the positions of the $[2 \mathrm{Fe}-2 \mathrm{~S}]$ clusters and conserved cysteine residues. The structure of Shethna protein I will provide information for understanding its function in relation to nitrogen fixation and its evolutionary relationships to other ferredoxins.

\section{Introduction}

Azotobacter vinelandii is a model organism for nitrogen fixation (Peters et al., 1995). Although nitrogenase is inactivated by oxygen, $A$. vinelandii can grow in above-atmospheric concentrations of oxygen (Maier \& Moshiri, 2000). This oxygen resistance arises via at least two mechanisms: firstly a high respiratory rate, which removes oxygen, called 'respiratory protection' (Jones et al., 1973), and secondly 'conformational protection', in which high oxygen levels pause nitrogenase activity, but on their removal nitrogen fixation resumes. Conformational protection is mediated by [2Fe-2S] protein II (FeSII) or Shethna protein, which forms a complex with nitrogenase that is catalytically inactive but resistant to oxygen (Robson, 1979; Moshiri et al., 1994; Schlesier et al., 2016). The FeSII protein was first purified by Shethna in the 1960s (Shethna et al., 1964, 1968) as a nonheme iron protein of interest, together with another protein, the so-called Shethna protein I or $[2 \mathrm{Fe}-2 \mathrm{~S}]$ protein I (FeSI).

Ferredoxins are iron-sulfur proteins that mediate electron transfer, and there are several families of them. $2 \mathrm{Fe}$ ferredoxins can be classified as plant-type, mitochondrial-type and bacterial ferredoxins. There is also another class comprising $3 \mathrm{Fe}, 4 \mathrm{Fe}, 7 \mathrm{Fe}$ and $8 \mathrm{Fe}$ ferredoxins with one or two FeS clusters of the cubane type (Zanetti \& Pandini, 2013). FeSI is a member of the thioredoxin-like ferredoxin family (InterPro family IPR009737). Thioredoxins have no Fe-S clusters, but have pairs of cysteine residues to exchange disulfide-bond oxidation states (Saarinen et al., 1995). These thioredoxin-like 
ferredoxins are also present in some multimeric hydrogenases (Appel \& Schulz, 1996; De Luca et al., 1998) and the NADHubiquinone oxidoreductase of respiratory chains (Yano et al., 1994).

In the A. vinelandii genome (Setubal et al., 2009), several genes encode proteins associated with nitrogen fixation. The dinitrogen reductase in the nitrogenase system is the MoFe protein. The major nif cluster of genes contains the nitrogenase structural genes, including those for MoFe and most of the nitrogenase-assembly factors. FeSI is in the middle of the major nif cluster, just after the nifN, nifE and nif $X$ genes which encode nitrogenase-assembly factors. FeSI is predicted to be cotranscribed with a $[4 \mathrm{Fe}-4 \mathrm{~S}]$ ferredoxin-like protein and several other proteins of unknown function (Fig. 1a). Moreover, the transcript level of FeSI was reported to increase 2.3-fold under nitrogen-fixing conditions (Hamilton et al., 2011). Therefore, given the genomic location and transcript data, it is likely that FeSI plays some role in nitrogen fixation.

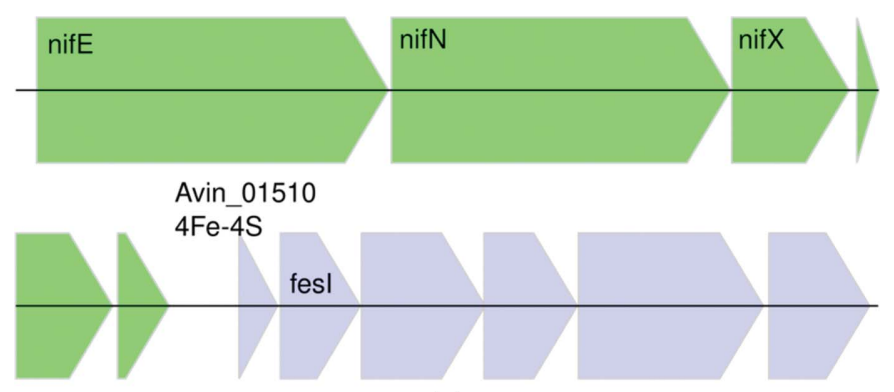

(a)

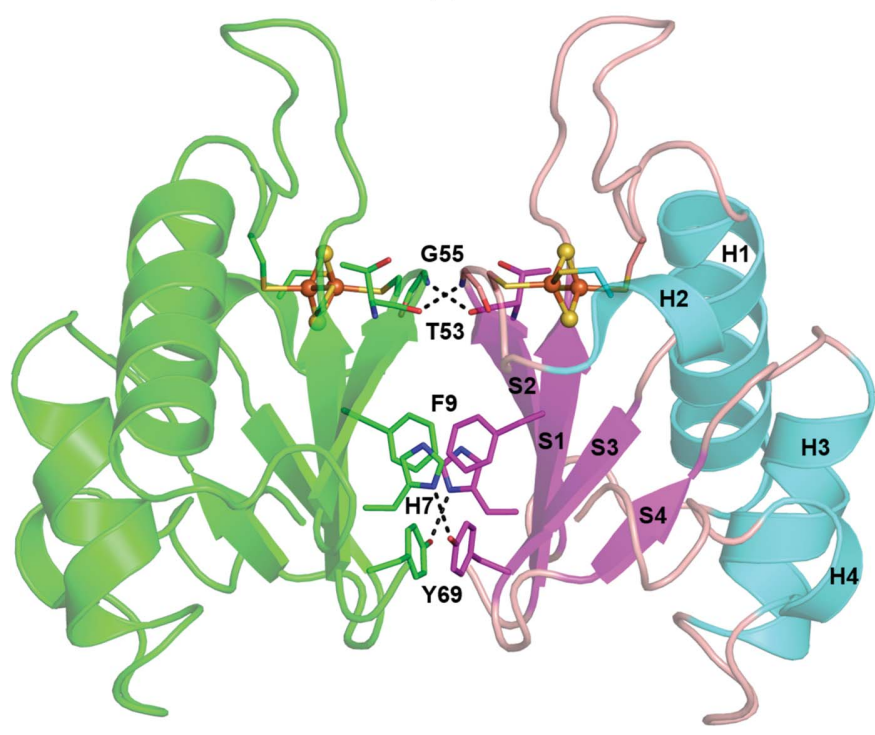

(b)

Figure 1

(a) Part of the major nif region showing the nifENX operon (green) and the operon encoding FeSI (blue). Genes of known function are labelled. FeSI is immediately preceded by Avin_01510, a predicted (4Fe-4S) ferredoxin. (b) Cartoon view of the A. vinelandii FeSI homodimer. Subunits are shown with the $[2 \mathrm{Fe}-2 \mathrm{~S}]$ clusters and ligating cysteine residues shown as sticks. The right subunit is coloured according to the secondary structure. Strands (S1-S4), helices (H1-H4) and loops are shown in magenta, cyan and salmon, respectively. The residues (His7, Phe9, Thr53, Gly55 and Tyr69) at the dimer interface are shown as sticks. Hydrogen bonds are shown as black dashed lines.
Table 1

Macromolecule-production information.

\begin{tabular}{ll}
\hline Source organism & A. vinelandii CA \\
DNA source & A. vinelandii CA genomic DNA \\
Forward primer (vector) & GGATCCACGCGGAACCAGACC \\
Reverse primer (vector) & GCCCGAAAGGAAGCTGAGTTGGCT \\
Forward primer (genomic DNA) & GGTCTGGTTCCGGTGGATCCATGGCCAAA \\
& CCCGAGTTCCATATC \\
Reverse primer (genomic DNA) & AGCCAACTCAGCTTCCTTTCGGGCCTACCA \\
& GATCTCGGCAGGGGT \\
Expression vector & pRSET-A \\
Expression host & E. coli (KRX) \\
Complete amino-acid sequence & MRGSHHHHHGLVPRGSMAKPEFHIFICAQ \\
\multicolumn{1}{c}{ of the construct produced } & NRPAGHPRGSCGAKGAEGVYNAFAQVLI \\
& QKNLTNRIALTTTGCLGPCQAGANVLIY \\
& PGAVMYSWVEPADAAIIVEQHLLGGEPY \\
& ADKLTPAEIW \\
\hline
\end{tabular}

FeSI is homologous to the $[2 \mathrm{Fe}-2 \mathrm{~S}]$ ferredoxin from Clostridium pasteurianum (Chatelet \& Meyer, 1999), which interacts with the $C$. pasteurianum nitrogenase MoFe protein (Golinelli et al., 1997) and is in the anf (iron-only) nitrogenase gene cluster of the C. pasteurianum genome (Pyne et al., 2014).

\section{Materials and methods}

\subsection{Macromolecule production}

The fesI gene (Avin_01520) was amplified by PCR from A. vinelandii CA genomic DNA and cloned by Gibson assembly (Gibson, 2011) into a modified pRSET-A vector with a thrombin-cleavable $6 \times$ His tag. The primers (Invitrogen) used for the pRSET-A vector were 5'-GGATCCACGCGG AACCAGACC-3' (forward) and 5'-GCCCGAAAGGAAG CTGAGTTGGCT-3' (reverse), and those for the genomic DNA were 5'-GGTCTGGTTCCGCGTGGATCCATGGCCA AACCCGAGTTCCATATC-3' (forward) and 5'-AGCCAA CTCAGCTTCCTTTCGGGCCTACCAGATCTCGGCAGG GGT-3' (reverse). The FesI-pRSET-A plasmid was transformed into Escherichia coli KRX cells. The cells were grown in 11 Terrific Broth to an OD of 0.6-0.8 and were then induced with $0.1 \%(w / v)$ rhamnose. The cells were grown at $18^{\circ} \mathrm{C}$ for $18 \mathrm{~h}$ after induction, spun at $4000 \mathrm{~g}$ for $15 \mathrm{~min}$, resuspended in $50 \mathrm{~m} M$ Tris- $\mathrm{HCl} \mathrm{pH} 7.9,150 \mathrm{mM} \mathrm{NaCl}$ and disrupted by sonication. Cell debris was removed by centrifugation and filtration. The supernatant was loaded onto a nickel resin affinity column (Generon) and eluted with $500 \mathrm{~m} M$ imidazole in $50 \mathrm{~m} M$ Tris- $\mathrm{HCl} \mathrm{pH} 7.9,150 \mathrm{~m} M \mathrm{NaCl}$. The His tag was cleaved by adding $50 \mathrm{U}$ thrombin (Sigma) and incubating at $4{ }^{\circ} \mathrm{C}$ overnight. Finally, the protein was concentrated to $\sim 15 \mathrm{mg} \mathrm{ml}^{-1}$ for crystallization trials. Macromoleculeproduction information is summarized in Table 1.

\subsection{Crystallization}

Thin plate-shaped crystals, which belonged to space group $P 2_{1}$, were obtained by sitting-drop vapour diffusion using a reservoir solution consisting of $0.1 M$ HEPES $\mathrm{pH} 7.5$, $70 \%(v / v)$ MPD (2,4-methylpentanediol). Crystals were cryoprotected in the mother liquor with $\sim 30 \%(v / v)$ polyethylene 
Table 2

Crystallization.

\begin{tabular}{|c|c|}
\hline Method & Sitting-drop vapour diffusion \\
\hline Plate type & 96-well plate \\
\hline Temperature (K) & 290 \\
\hline Protein concentration $\left(\mathrm{mg} \mathrm{ml}^{-1}\right)$ & 15 \\
\hline $\begin{array}{l}\text { Buffer composition of protein } \\
\text { solution }\end{array}$ & $50 \mathrm{~m} M$ Tris- $\mathrm{HCl}$ pH 7.9, $150 \mathrm{~m} M \mathrm{NaCl}$ \\
\hline Composition of reservoir solution & $0.1 M$ HEPES $\mathrm{pH} 7.5,70 \%(v / v)$ MPD \\
\hline Volume and ratio of drop & $200 \mathrm{nl}(1: 1)$ and $300 \mathrm{nl}(2: 1)$ \\
\hline Volume of reservoir $(\mu \mathrm{l})$ & 50 \\
\hline
\end{tabular}

Table 3

Data collection and processing.

Values in parentheses are for the outer shell.

\begin{tabular}{ll}
\hline Diffraction source & I03, Diamond Light Source \\
Wavelength $(\AA)$ & 1.734 \\
Temperature $(\mathrm{K})$ & 100 \\
Detector & PILATUS \\
Crystal-to-detector distance $(\mathrm{mm})$ & 185 \\
Rotation range per image $\left({ }^{\circ}\right)$ & 0.2 \\
Total rotation range $\left({ }^{\circ}\right)$ & 180 \\
Exposure time per image $(\mathrm{s})$ & 0.1 \\
Space group & $P 12_{1} 1$ \\
$a, b, c(\AA)$ & $39.04,60.10,45.51$ \\
$\alpha, \beta, \gamma\left({ }^{\circ}\right)$ & $90,109.37,90$ \\
Resolution range $(\AA)$ & $42.93-2.11(2.16-2.11)$ \\
No. of unique reflections & $11386(859)$ \\
Completeness $(\%)$ & $98.7(97.9)$ \\
Multiplicity & $3.1(3.0)$ \\
$\langle I / \sigma(I)\rangle$ & $8.1(2.4)$ \\
Overall $B$ factor from Wilson plot $\left(\AA^{2}\right)$ & 21.4
\end{tabular}

glycol (PEG) 400 and then flash-cooled in liquid nitrogen. Crystallization information is summarized in Table 2.

\subsection{Data collection and processing}

X-ray diffraction data were collected from cryoprotected crystals at $100 \mathrm{~K}$ on beamline I03 at Diamond Light Source, UK. For phase determination, a data set was collected at the Fe $K$-edge at a wavelength of $1.734 \AA$ A. The collected data were processed and scaled with xia2 (Winter, 2010) using the $3 \mathrm{di} i$ $(X D S)$ setting (Kabsch, 2010). Data-collection and processing statistics are given in Table 3.

\subsection{Structure solution and refinement}

Phases were calculated with the AUTOSHARP pipeline (Vonrhein et al., 2007) and an initial model was built with ARP/wARP (Langer et al., 2008). Cycles of model building and refinement with noncrystallographic symmetry restraints were performed in REFMAC5 (Murshudov et al., 2011) and Coot (Emsley et al., 2010). MolProbity (Williams et al., 2018) was used for validation. The final refinement statistics are presented in Table 4. Figures were drawn with PyMOL (DeLano, 2002).

\section{Results and discussion}

The $A$. vinelandii FeSI structure is a homodimer burying $1420 \AA^{2}$ as calculated with the PDBePISA service at EMBLEBI (Krissinel \& Henrick, 2007). It consists of a sheet with
Table 4

Structure refinement.

Values in parentheses are for the outer shell.

\begin{tabular}{ll}
\hline Resolution range $(\AA)$ & $42.9-2.1(2.165-2.110)$ \\
Completeness (\%) & $98.5(97.9)$ \\
No. of reflections, working set & $11386(827)$ \\
No. of reflections, test set & $545(29)$ \\
Final $R_{\text {cryst }}$ & 0.177 \\
Final $R_{\text {free }}$ & 0.231 \\
No. of non-H atoms & \\
$\quad$ Protein & 1558 \\
$\quad$ Ligand & 8 \\
$\quad$ Solvent & 128 \\
$\quad$ Total & 1694 \\
R.m.s. deviations & \\
$\quad$ Bonds $(\AA)$ & 0.024 \\
$\quad$ Angles $\left({ }^{\circ}\right)$ & 2.373 \\
Average $B$ factors $\left(\AA^{2}\right)$ & \\
$\quad$ Protein & 35.6 \\
$\quad$ Ligand & 23.4 \\
$\quad$ Water & 43.0 \\
Ramachandran plot & \\
$\quad$ Favoured regions $(\%)$ & 97.0 \\
$\quad$ Additionally allowed $(\%)$ & 3.0 \\
\hline
\end{tabular}

four $\beta$-strands, two long $\alpha$-helices that pack against the sheet, two short $\alpha$-helices and several loops. The sheet from the monomer packs against its symmetry mate, forming the dimer interface. On one side of the dimer interface, two hydrogen bonds in parallel strands ( $\mathrm{S} 1$ and S3) between the side chains of His7 and Tyr69 of two chains and, on the other side, hydrogen bonding between the main chains of Thr53 and Gly55 on strand S2 of two chains, along with the interaction of Phe9 with its symmetry mate through $\pi$-stacking, favour the dimerization (Fig. 1b). The two chains are similar, with an

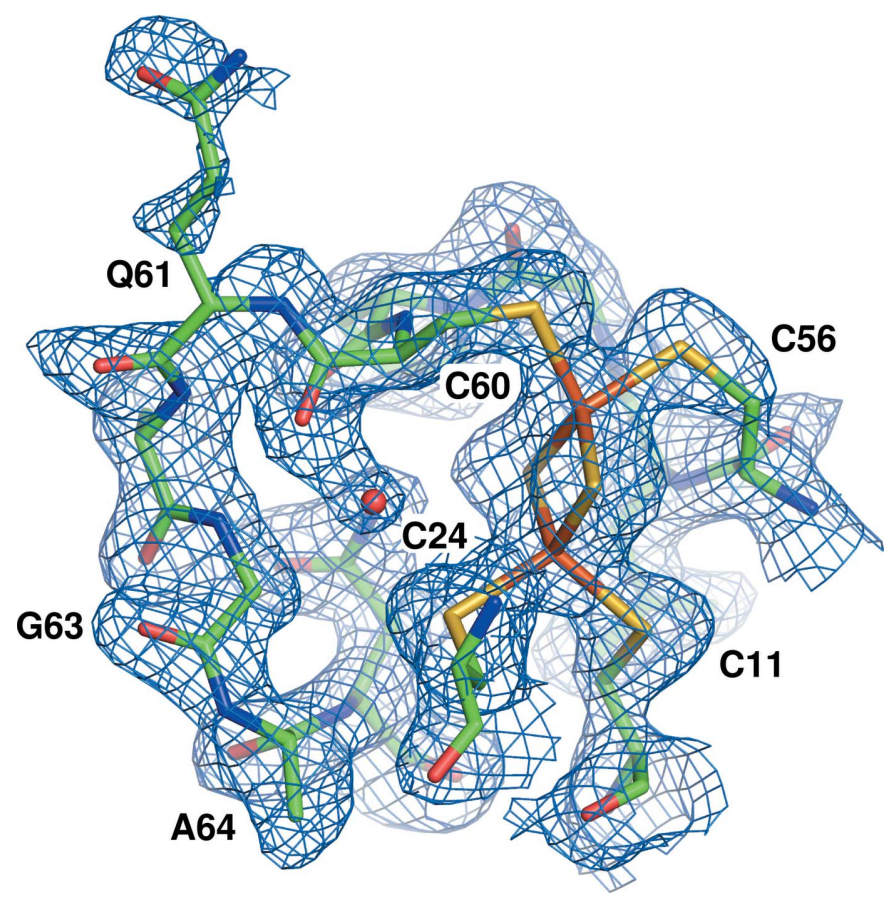

Figure 2

FeSI electron density $\left(2 F_{\mathrm{o}}-F_{\mathrm{c}}\right)$ contoured at $1 \sigma$ around the [2Fe-2S] cluster in chain $A$, with residues of interest labelled. The Gly63-Ala64 bond is a cis-peptide. 


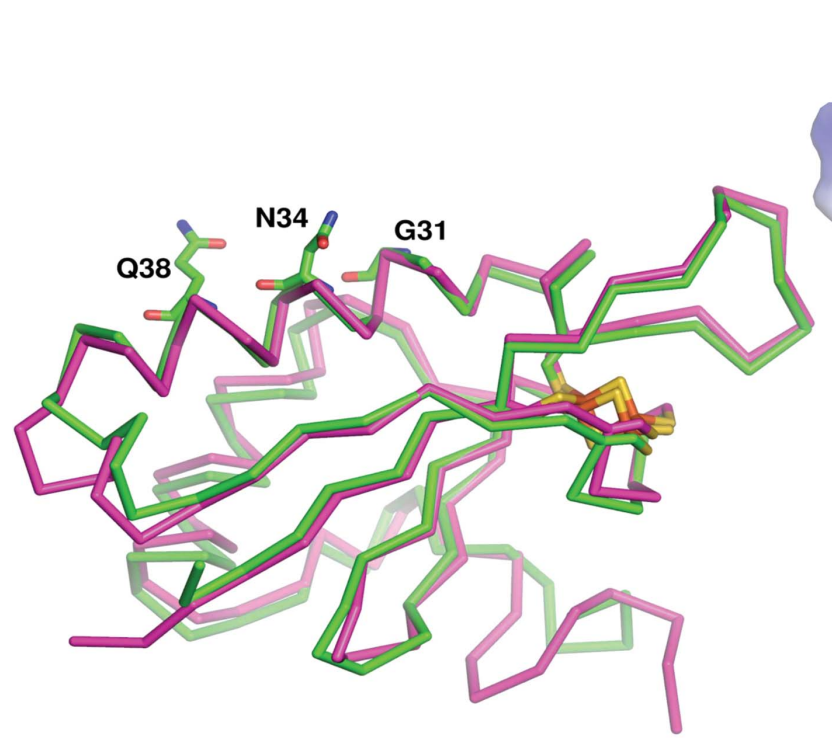

(a)

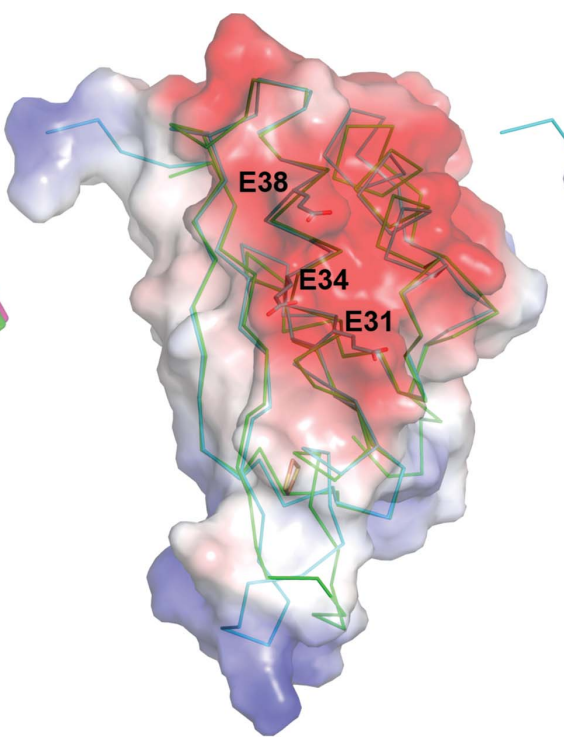

(b)

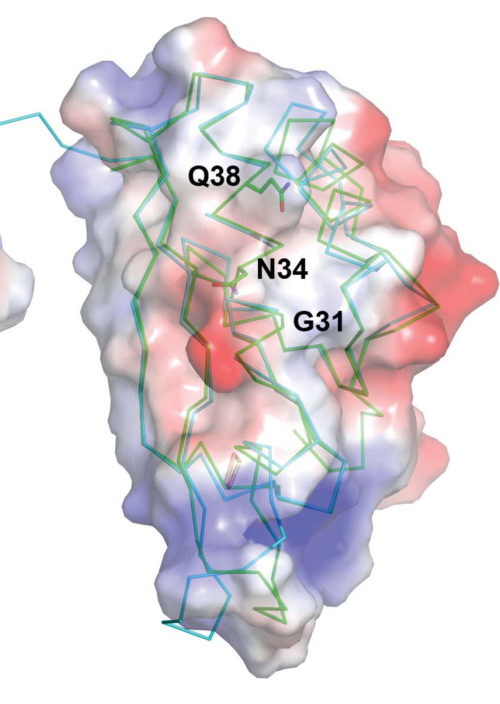

(c)

Figure 3

(a) Superposition of FeSI from A. vinelandii (green) and the [2Fe-2S] ferredoxin from A. aeolicus (magenta; PDB entry 1f37). In FeSI, Gly31, Asn34 and Gln38 are shown as sticks. (b) Electrostatic surface representation of the predicted model of the C. pasteurianum [2Fe-2S] protein and its superposition with FeSI, shown as cyan (C. pasteurianum [2Fe-2S] protein) and green (FeSI) ribbons. The key residues (Glu31, Glu34 and Glu38) forming the negatively charged surface are highlighted as sticks. (c) Electrostatic surface representation of FeSI and its superposition with the model of the C. pasteurianum $[2 \mathrm{Fe}-2 \mathrm{~S}]$ protein, shown as coloured ribbons. The key residues (Gly31, Asn34 and Gln38) are highlighted as sticks.

r.m.s.d. of $0.1 \AA$ over $104 \mathrm{C}^{\alpha}$ atoms. Both clusters are coordinated in the same way and were refined at $100 \%$ occupancy. The $[2 \mathrm{Fe}-2 \mathrm{~S}]$ cluster is positioned between two loops that are located between strand S1 and helix $\mathrm{H} 1$ and between strand S2 and helix H2. It is bound to four cysteine residues: Cys11, Cys24, Cys56 and Cys60. There is a nonproline cis-peptide, well resolved in the density, between Gly63 and Ala64 (Fig. 2), which are Gly-Pro in many homologous sequences (Supplementary Fig. S1).

The most similar protein to FeSI with a known structure is the [2Fe-2S] ferredoxin from Aquifex aeolicus (Chatelet et al., 1999; Yeh et al., 2000), with an r.m.s.d. of $2 \AA$ over one chain and $38 \%$ sequence identity. A. aeolicus does not fix nitrogen, so its thioredoxin-like ferredoxin must have a function that is unrelated to nitrogen fixation.

FeSI has $31 \%$ sequence identity to the C. pasteurianum ferredoxin (Chatelet \& Meyer, 1999), which has no experimental structure. The structure of $C$. pasteurianum ferredoxin was predicted in trRosetta (Yang et al., 2020) and the model has an r.m.s.d. of $0.6 \AA$ to FeSI over one chain. C. pasteurianum ferredoxin specifically and strongly interacts electrostatically with the nitrogenase protein MoFe via three negatively charged residues: Glu31, Glu34 and Glu38 (Golinelli et al., 1997). These residues are on an $\alpha$-helix on the opposite side of the protein to the $[2 \mathrm{Fe}-2 \mathrm{~S}]$ cluster. In FeSI, the equivalent residues are Gly31, Asn34 and Gln38, all of which are on the outside face of the first helix of the structure (Fig. 3). The change in charge from three negative glutamates to a neutral glutamine, asparagine and glycine suggests that it is unlikely that FeSI interacts directly with $A$. vinelandii $\mathrm{MoFe}$ by this mechanism and that its involvement in nitrogen fixa- tion is of a different nature to the $C$. pasteurianum protein. Moreover, previous cross-linking experiments did not find any interaction of FeSI with the $C$. pasteurianum or $A$. vinelandii MoFe proteins (Chatelet \& Meyer, 1999).

The FeSI structure completes the structural picture of the original two Azotobacter FeS proteins purified by Shethna in the 1960s. The structure of the FeSI protein from $A$. vinelandii appears to be a typical thioredoxin-like ferredoxin and will provide information for understanding its function in relation to nitrogen fixation and its evolutionary relationships to other ferredoxins.

\section{Acknowledgements}

We thank Diamond Light Source for X-ray beam time (proposal mx9424) and the staff of beamlines I03 and I04 for assistance with crystal testing and data collection. The crystallization facility at Imperial College was funded by BBSRC (BB/D524840/1) and the Wellcome Trust (202926/Z/16/Z).

\section{Funding information}

This work was funded in part by grant BB/L011468/1 from the Biotechnology and Biological Sciences Research Council/ National Science Foundation Nitrogen Ideas Lab: OxygenTolerant Nitrogenase. BVK is supported by a TUBİTAK 2232 Fellowship (Project No. 118C225). CARC was supported by a BBSRC Doctoral Training Programme grant (BB/F017324/1).

\section{References}

Appel, J. \& Schulz, R. (1996). Biochim. Biophys. Acta, 1298, 141-147. 
Chatelet, C., Gaillard, J., Pétillot, Y., Louwagie, M. \& Meyer, J. (1999). Biochem. Biophys. Res. Commun. 261, 885-889.

Chatelet, C. \& Meyer, J. (1999). J. Biol. Inorg. Chem. 4, 311-317.

DeLano, W. L. (2002). PyMOL. http://www.pymol.org.

De Luca, G., Asso, M., Bélaïch, J.-P. \& Dermoun, Z. (1998). Biochemistry, 37, 2660-2665.

Emsley, P., Lohkamp, B., Scott, W. G. \& Cowtan, K. (2010). Acta Cryst. D66, 486-501.

Gibson, D. G. (2011). Methods Enzymol. 498, 349-361.

Golinelli, M.-P., Gagnon, J. \& Meyer, J. (1997). Biochemistry, 36, 11797-11803.

Hamilton, T. L., Ludwig, M., Dixon, R., Boyd, E. S., Dos Santos, P. C., Setubal, J. C., Bryant, D. A., Dean, D. R. \& Peters, J. W. (2011). J. Bacteriol. 193, 4477-4486.

Jones, C. W., Brice, J. M., Wright, V. \& Ackrell, B. A. C. (1973). FEBS Lett. 29, 77-81.

Kabsch, W. (2010). Acta Cryst. D66, 133-144.

Krissinel, E. \& Henrick, K. (2007). J. Mol. Biol. 372, 774-797.

Langer, G., Cohen, S. X., Lamzin, V. S. \& Perrakis, A. (2008). Nat. Protoc. 3, 1171-1179.

Maier, R. J. \& Moshiri, F. (2000). J. Bacteriol. 182, 3854-3857.

Moshiri, F., Kim, J. W., Fu, C. \& Maier, R. J. (1994). Mol. Microbiol. 14, 101-114.

Murshudov, G. N., Skubák, P., Lebedev, A. A., Pannu, N. S., Steiner, R. A., Nicholls, R. A., Winn, M. D., Long, F. \& Vagin, A. A. (2011). Acta Cryst. D67, 355-367.

Peters, J. W., Fisher, K. \& Dean, D. R. (1995). Annu. Rev. Microbiol. 49, 335-366.

Pyne, M. E., Utturkar, S., Brown, S. D., Moo-Young, M., Chung, D. A. \& Chou, C. P. (2014). Genome Announc. 2, e00790-14.

Robson, R. L. (1979). Biochem. J. 181, 569-575.

Saarinen, M., Gleason, F. K. \& Eklund, H. (1995). Structure, 3, 10971108 .
Schlesier, J., Rohde, M., Gerhardt, S. \& Einsle, O. (2016). J. Am. Chem. Soc. 138, 239-247.

Setubal, J. C., dos Santos, P., Goldman, B. S., Ertesvåg, H., Espin, G., Rubio, L. M., Valla, S., Almeida, N. F., Balasubramanian, D., Cromes, L., Curatti, L., Du, Z., Godsy, E., Goodner, B., HellnerBurris, K., Hernandez, J. A., Houmiel, K., Imperial, J., Kennedy, C., Larson, T. J., Latreille, P., Ligon, L. S., Lu, J., Maerk, M., Miller, N. M., Norton, S., O'Carroll, I. P., Paulsen, I., Raulfs, E. C., Roemer, R., Rosser, J., Segura, D., Slater, S., Stricklin, S. L., Studholme, D. J., Sun, J., Viana, C. J., Wallin, E., Wang, B., Wheeler, C., Zhu, H., Dean, D. R., Dixon, R. \& Wood, D. (2009). J. Bacteriol. 191, 45344545.

Shethna, Y. I., DerVartanian, D. V. \& Beinert, H. (1968). Biochem. Biophys. Res. Commun. 31, 862-868.

Shethna, Y. I., Wilson, P. W., Hansen, R. E. \& Beinert, H. (1964). Proc. Natl Acad. Sci. USA, 52, 1263-1271.

Vonrhein, C., Blanc, E., Roversi, P. \& Bricogne, G. (2007). Methods Mol. Biol. 364, 215-230.

Williams, C. J., Headd, J. J., Moriarty, N. W., Prisant, M. G., Videau, L. L., Deis, L. N., Verma, V., Keedy, D. A., Hintze, B. J., Chen, V. B., Jain, S., Lewis, S. M., Arendall, W. B., Snoeyink, J., Adams, P. D., Lovell, S. C., Richardson, J. S. \& Richardson, D. C. (2018). Protein Sci. 27, 293-315.

Winter, G. (2010). J. Appl. Cryst. 43, 186-190.

Yang, J., Anishchenko, I., Park, H., Peng, Z., Ovchinnikov, S. \& Baker, D. (2020). Proc. Natl Acad. Sci. USA, 117, 1496-1503.

Yano, T., Sled, V. D., Ohnishi, T. \& Yagi, T. (1994). Biochemistry, 33, 494-499.

Yeh, A. P., Chatelet, C., Soltis, S. M., Kuhn, P., Meyer, J. \& Rees, D. C. (2000). J. Mol. Biol. 300, 587-595.

Zanetti, G. \& Pandini, V. (2013). Encyclopedia of Biological Chemistry, 2nd ed., edited by W. J. Lennarz \& M. D. Lane, pp. 296-298. New York: Academic Press. 